\title{
Comment on "Computer simulations on sprite initiation for realistic lightning models with higher-frequency surges" by T. Asano, T. Suzuki, Y. Hiraki, E. Mareev, M. G. Cho, and M. Hayakawa
}

\author{
Leandro Z. S. Campos ${ }^{1,2}$ and Marcelo M. F. Saba ${ }^{1}$ \\ Received 6 April 2009; revised 25 August 2009; accepted 15 October 2009; published 31 December 2009.
}

Citation: Campos, L. Z. S., and M. M. F. Saba (2009), Comment on "Computer simulations on sprite initiation for realistic lightning models with higher-frequency surges” by T. Asano, T. Suzuki, Y. Hiraki, E. Mareev, M. G. Cho, and M. Hayakawa, J. Geophys. Res., 114, A12324, doi:10.1029/2009JA014335.

\section{Introduction}

[1] The aim of this comment is to provide and discuss some observational support to the assumptions made by Asano et al. [2009] for computer simulations on sprite initiation. In a previous work, Asano et al. [2008] analyzed the sprite initiation assuming the occurrence of only a single return stroke (RS). However, the question on the longdelayed sprites with respect to their parent cloud-to-ground (CG) lightning, sometimes longer than $100 \mathrm{~ms}$ [Bell et al., 1998; Lyons, 2006; Mika and Haldoupis, 2008], was not answered by Asano et al. [2008]. Previous studies indicate a strong correlation between long-delayed sprites and continuing currents (CC) [e.g., Cummer and Füllekrug, 2001; Lyons, 2006]. In fact, Yashunin et al. [2007] suggested, based on numerical calculations, that $\mathrm{M}$ components are potentially responsible for the occurrence of delayed sprites and sprite halos.

[2] Diverse works [e.g., Boccippio et al., 1995; Cho and Rycroft, 2001; Moudry et al., 2003] point that one cause for the occurrence of red sprites (and other transient luminous events) that occur at high altitudes is the horizontally extensive flashes that transfer large amounts of positive charge to ground. More recently, Mika and Haldoupis [2008] found that intracloud lightning has a strong influence on sprite morphology; Saba et al. [2008, 2009] showed, through high-speed video observations of positive lightning leaders, a close relation between $+\mathrm{CG}$ and intracloud flashes, and Kudintseva et al. [2009] made a theoretical study on the electric field of a lightning channel with a long horizontal section from an elevated observer, stressing the importance of such morphology for future sprite modeling. Considering that $\mathrm{M}$ components propagate through the entire extension of the lightning channel and that larger amounts of positive charge transfer to ground occur due to long CC, we believe that these two linked phenomena play an important role in the physics of transient luminous events (TLEs).

\footnotetext{
${ }^{1}$ National Institute for Space Research, São José dos Campos, Brazil.

${ }^{2}$ Also at Departamento de Física e Química, UNESP, Guaratinguetá, Brazil.

Copyright 2009 by the American Geophysical Union. 0148-0227/09/2009JA014335\$09.00
}

[3] Asano et al. [2009] include the presence of $\mathrm{M}$ components superimposed on the lightning CC to obtain a more realistic simulation of the production of sprites. Knowing that thousands cases of +CG-induced sprites have been observed and that remarkably few observations associate sprites with negative polarity ground flashes [Barrington-Leigh et al., 1999; São Sabbas et al., 2003; Williams, 2006; Williams et al., 2007], Asano et al. [2009] focus on reproducing the simulation of $+\mathrm{CG}$ followed by $\mathrm{CC}$ with $\mathrm{M}$ components.

[4] However, as noted by Asano et al. [2009, paragraph 17], "almost all of the literature on $M$ components is based on negative lightning discharges (triggered and natural) [Rakov et al., 1992; Fisher et al., 1993; Thottappillil et al., 1990, 1995; Campos et al., 2007], and it seems that there are no papers on the characteristics of $\mathrm{M}$ components for the positive lightning discharge." As a consequence, they assume that the parameters of $\mathrm{CC}$ and $\mathrm{M}$ components observed by Campos et al. [2007] for natural -CG are valid also for $+\mathrm{CG}$ flashes. For this very reason, section 2 will discuss the very recent observational data published by Campos et al. [2009] concerning $\mathrm{M}$ components in $+\mathrm{CG}$ lightning.

\section{Discussion of the Parameters of Continuing Currents and M Components for Positive Cloud-to-Ground Flashes}

[5] In a very recent paper, Campos et al. [2009] presented parameters of $\mathrm{M}$ components and statistics on $\mathrm{CC}$ waveshapes for $+\mathrm{CG}$ flashes obtained from high-speed video observations using the same instrumentation and methodology developed by Campos et al. [2007]. In the following sessions we review some of the assumptions made by Asano et al. [2009] in their simulations by analyzing and comparing the $\mathrm{M}$ components data set of both polarities analyzed by Campos et al. [2007, 2009].

\subsection{Continuing Current Waveshape and Duration}

[6] Asano et al. [2009, paragraph 17] cite the percentage of negative strokes that are followed by $\mathrm{CCs}$ of any duration reported by Ballarotti et al. [2005]. They also add that for positive cases "it seems likely that this percentage would be significantly higher than that of negative discharges" [Asano et al., 2009, paragraph 17]. In fact, according to observations done with high-speed cameras, M. M. F. Saba 
Table 1. Textual Description of Each CC Waveshape Type Considered in the Literature and a Summary of the Statistical Results of Fisher et al. [1993] and Campos et al. [2007, 2009] ${ }^{\mathrm{a}}$

\begin{tabular}{llccc}
\hline & \multicolumn{1}{c}{ Description } & $\begin{array}{c}\text { Triggered } \\
\text { Type }\end{array}$ & $\begin{array}{c}\text { Negative CG } \\
\text { [Cisher et al., 1993] }\end{array}$ & $\begin{array}{c}\text { Positive CG } \\
\text { [Campos et al., 2009] }\end{array}$ \\
\hline I & more or less exponential decay & $47 \%(14)$ & $24 \%(15)$ & $24 \%(5)$ \\
II & hump followed by a gradual decay & $36 \%(11)$ & $6 \%(4)$ & $24 \%(5)$ \\
III & gradual increase and decrease & $10 \%(3)$ & $16 \%(10)$ & $0 \%(0)$ \\
IV & hump followed by a long-lasting steady plateau & $7 \%(2)$ & $8 \%(5)$ & $9 \%(2)$ \\
V & two or more humps & - & $11 \%(7)$ & $0 \%(0)$ \\
VI & low-intensity plateau & - & $35 \%(22)$ & $43 \%(9)$ \\
Total & & $100 \%(30)$ & $100 \%(63)$ & $100 \%(21)$ \\
\hline
\end{tabular}

${ }^{a}$ Adapted from Campos et al. [2009, Table 2] with permission from Elsevier.

et al. (High-speed video observations of positive lightning, paper presented at IX International Symposium on Lightning Protection, Institute of Electrotechnics And Energy, Foz do Iguaçu, Paraná, Brazil, 2007) found that $74 \%$ of $39+\mathrm{CG}$ flashes contained at least one long CC (duration greater than $40 \mathrm{~ms}$ ). Previously, Saba et al. [2006] also reported that while $-\mathrm{CG}$ strokes with peak current higher than $20 \mathrm{kA}$ are never followed by long CC, +CG strokes are not bound to this limitation.

[7] In order to compute realistic lightning models in their simulations, Asano et al. [2009] created 3 different cases (shown in their Figure 2). Cases 1 and 2 simulate a RS with no $\mathrm{CC}$ but with subsequent high-frequency surges (that they called "pseudo M components"). Case 3 represents one RS (with a lower peak current compared to cases 1 and 2) followed by a low-level $\mathrm{CC}$ with $\mathrm{M}$ components superimposed. The lightning current waveform in case 3 seems to represent "the situation most likely reflecting the positive lightning case with M components" [Asano et al., 2009, paragraph 18]. They argue that this fact is supported by the analysis on $\mathrm{CC}$ waveshapes for negative lightning made by Campos et al. [2007] due to its similarity to types I (more or less exponential decay) and VI (low-intensity plateau).

[8] Fisher et al. [1993] made the first analysis of CC waveshape based on channel current measurements of triggered lightning, dividing 30 cases among four types (I-IV), grouped according to similar general characteristics. More recently, Campos et al. [2007] made the same analysis for 63 natural $-\mathrm{CG}$ cases based on luminosity variation provided by high-speed camera observations and suggested the creation of two additional types (V and VI). The two types cited by Asano et al. [2009] (I and VI) constitute approximately $59 \%$ of the CCs in negative flashes studied by Campos et al. [2007, Table 2]. The more recent paper by Campos et al. [2009] gives extra support to the assumptions made by Asano et al. [2009] as types I and VI constitute $67 \%$ of the 21 CCs studied in positive flashes. The CC waveshape types III (hump followed by a gradual decay), IV (hump followed by a long-lasting plateau) and V (two or more humps) differ most significantly from I and VI, and are either rather uncommon ( $9 \%$ for type IV) or apparently inexistent (types III and V) in positive flashes [Campos et al., 2009, Table 2]. An extended data set presented by L. Z. S. Campos et al. (Waveshapes of continuing currents from negative and positive cloud-to-ground flashes observed in southern Arizona, paper presented at 20th International Lightning Detection Conference, Vaisala, Tucson, Arizona, 2008) that included data obtained in southern Arizona does not change this statistics. For a clearer understanding of these results, Table 1 shows a textual description of each CC waveshape type and a summary of the statistical results discussed above [Fisher et al., 1993; Campos et al., 2007, 2009]. Graphical examples of the six waveshape types are illustrated in Figure 5 of Campos et al. [2007].

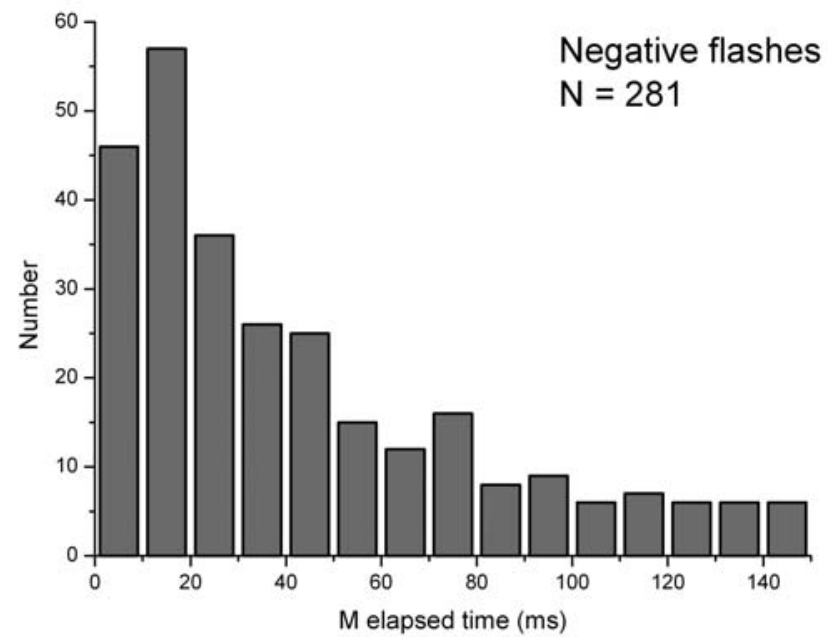

(a)

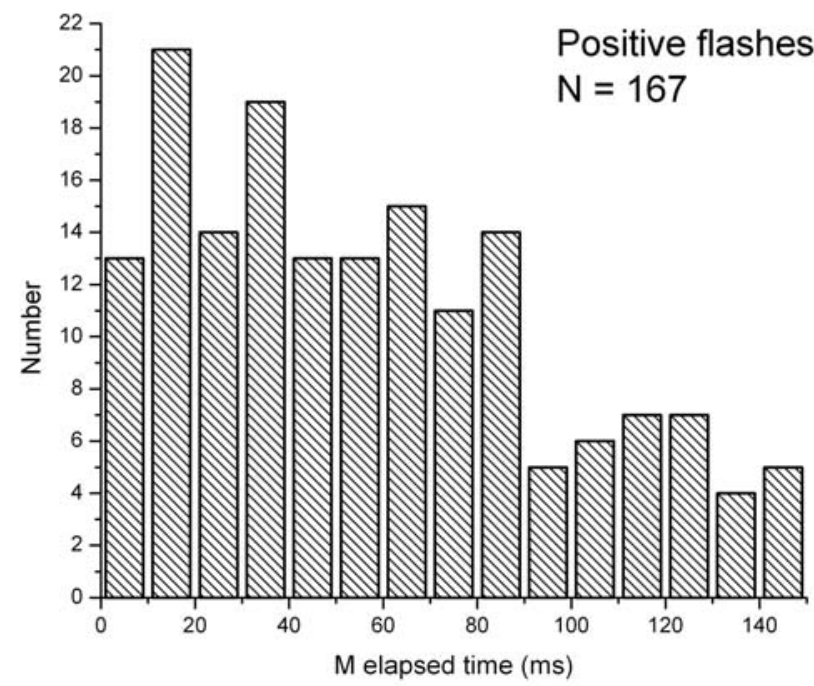

(b)

Figure 1. $M$ component elapsed time since the RS for (a) negative ( $81 \%$ of the data set by Campos et al. [2007]) and (b) positive flashes ( $88 \%$ of the data set by Campos et al. [2009]). Adapted from Campos et al. [2009, Figure 3 insets] with permission from Elsevier. 
Table 2. Summary of M Component Parameters Considered by Asano et al. [2009] Compared to the Observational Results Reported by Saba et al. [2006], M. M. F. Saba et al. (presented paper, 2007), and Campos et al. [2007, 2009]

\begin{tabular}{|c|c|c|c|}
\hline & \multicolumn{2}{|c|}{ Observational Results } & \multirow[b]{2}{*}{ Simulation Parameters } \\
\hline & Negative Flashes & Positive Flashes & \\
\hline & Saba et al. [2006] & M. M. F. Saba et al. (presented paper, 2007) & Asano et al. [2009] \\
\hline \multicolumn{4}{|l|}{ Continuing currents } \\
\hline \multirow[t]{4}{*}{ Duration, ms } & 4 to 542 & 7 to 360 & 16 \\
\hline & \multicolumn{2}{|c|}{ Observational Results } & \\
\hline & Negative Flashes & Positive Flashes & Simulation Parameters \\
\hline & Campos et al. [2007] & Campos et al. [2009] & Asano et al. [2009] \\
\hline \multicolumn{4}{|l|}{ M components } \\
\hline $\mathrm{M}$ elapsed time, $\mathrm{ms}$ & 10 to 20 (MR) & 10 to 20 (MR) & 4 to 12 \\
\hline $\mathrm{M}$ interval, $\mathrm{ms}$ & 5 to 10 (MR) & 0 to 5 (MR) & 2 or 4 \\
\hline Number of ms per CC & $3(\mathrm{M})$ & 6 and $8(M)$ & 3 \\
\hline
\end{tabular}

\subsection{Component Elapsed Time Since the Return Stroke and the Number of $M$ Components per Continuing Current}

[9] Asano et al. [2009] presented arguments linking the long delay of sprite initiation (in respect to the RS) to the occurrence of M components in their computer simulations. In order to do that, they use statistics of $\mathrm{M}$ components parameters obtained by Campos et al. [2007] for negative flashes. They have considered elapsed times from the RS to each $\mathrm{M}$ component ranging from 4 to $12 \mathrm{~ms}$ inside $16 \mathrm{~ms}$ long CCs. Even though these intervals are distant from the geometric mean (GM) observed for both negative $(42 \mathrm{~ms}$ [Campos et al., 2007]) and positive flashes $(52.5 \mathrm{~ms}$ [Campos et al., 2009]) they are coherent with the histograms obtained for both polarities also by Campos et al. [2007, 2009]. As shown in Figure 1 (adapted from Campos et al. [2009, Figure 3 insets]), the most common M component elapsed time values in -CG flashes lie between 0 and $20 \mathrm{~ms}$ from the RS; although in $+\mathrm{CG}$ flashes $\mathrm{M}$ components are more distributed through a wider temporal range. Table 2 summarizes and compares the results for these parameters.

[10] In a recent paper, Mika and Haldoupis [2008] have termed "short-delayed" sprites as those preceded by intervals of about $30 \mathrm{~ms}$ since the +CG stroke and "longdelayed" sprites as those preceded by intervals ranging from 30 to $220 \mathrm{~ms}$. While about $70 \%$ of their data set were considered to be short-delayed sprites, the remaining 30\% fit the long-delayed sprite classification, indicating that they may occur much more frequently than previously thought. These results seem to be consistent with what was reported by Campos et al. [2009] for M components of +CG flashes combined with the statistics on continuing current duration obtained by M. M. F. Saba et al. (presented paper, 2007). While in -CG more than $75 \%$ of the M components occur in the first half of the CC, in +CG flashes only $60 \%$ occur within this time range. According to Campos et al. [2009, p. 423], "it is noticeable that M components in negative flashes tend to group in the early periods of the continuing current while in positive flashes they are better distributed along the total duration." And, according to M. M. F. Saba et al. (presented paper, 2007), the values of CC duration range from 7 to $360 \mathrm{~ms}$ in +CG lightning, with a mean of $99 \mathrm{~ms}$ and $74 \%$ of the flashes containing at least one long CC.

[11] Furthermore, the average number of $\mathrm{M}$ components per $\mathrm{CC}$ is very distinctive from one polarity to the other; while for negative flashes Campos et al. [2007] observed 5.5 M components per CC, Campos et al. [2009] observed 9.0 for positive flashes. A new analysis of the $\mathrm{M}$ component data set studied by Campos et al. [2007, 2009] for this comment paper has provided us a mode value of $3 \mathrm{M}$ components per $\mathrm{CC}$ for $-\mathrm{CG}$ flashes and mode values of 6 and 8 for + CG flashes. As Asano et al. [2009] simulated particularly short CCs (16 ms of duration) with only $3 \mathrm{M}$ components, future works should present results for longer $\mathrm{CCs}$ with the presence of more frequent $\mathrm{M}$ components in order to address the question of long-delayed sprites. Table 2 summarizes the comparison between parameters made in the discussion above.

[12] We believe that these two works [Mika and Haldoupis, 2008; Campos et al., 2009] provide more observational support to the discussion made by Asano et al. [2009, section 5.3] concerning the timing of occurrence of $\mathrm{M}$ and pseudo $\mathrm{M}$ components in $+\mathrm{CG}$ lightning and their relation to long-delayed sprites. On the other hand, greater care should be taken when addressing this subject as it is important to stress which different considerations will be necessary to be assumed in future contributions.

\subsection{Time Interval Between Successive M Components}

[13] The lightning models considered in the simulations made by Asano et al. [2009] used time intervals of $2 \mathrm{~ms}$ or $4 \mathrm{~ms}$ between successive M components. As noted by the authors (in section 4.2.3), these intervals are smaller than the GM of $11 \mathrm{~ms}$ obtained for negative flashes by Campos et al. [2007]. They are, however, in better agreement with the values obtained by Campos et al. [2009]. In this paper, the GM of M component intervals for positive flashes is $8.6 \mathrm{~ms}$, the peak of occurrence of the histogram lies between 0 and $5 \mathrm{~ms}$ and $60 \%$ of the data set lasted less than $10 \mathrm{~ms}$. Figure 2, adapted from Campos et al. [2009, Figure 5 insets], illustrates the distribution of both polarities, showing the agreement between the intervals considered by Asano et al. [2009] and the observational results. This discussion is also summarized in Table 2 .

\section{Summary and Considerations on the Amplitude of M Components}

[14] The assumptions made by Asano et al. [2009] to obtain a more realistic lightning model for simulations of 


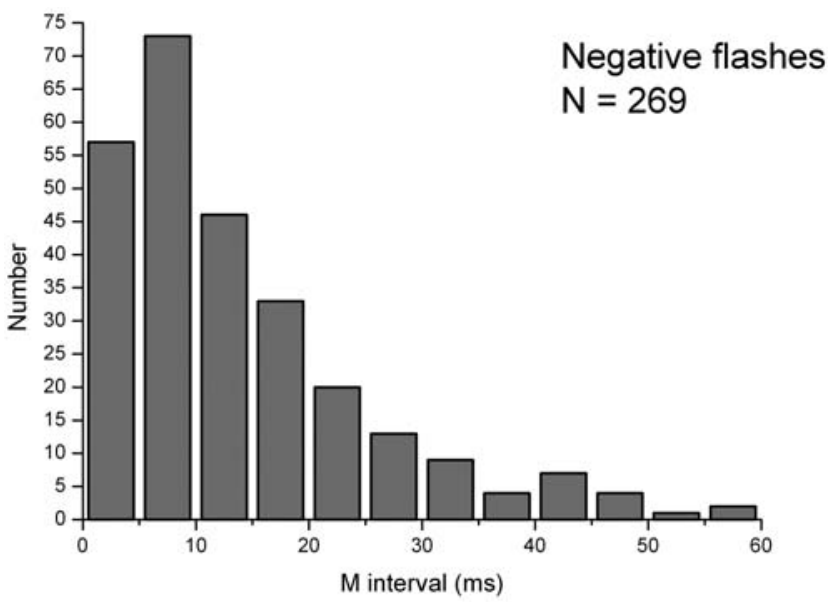

(a)

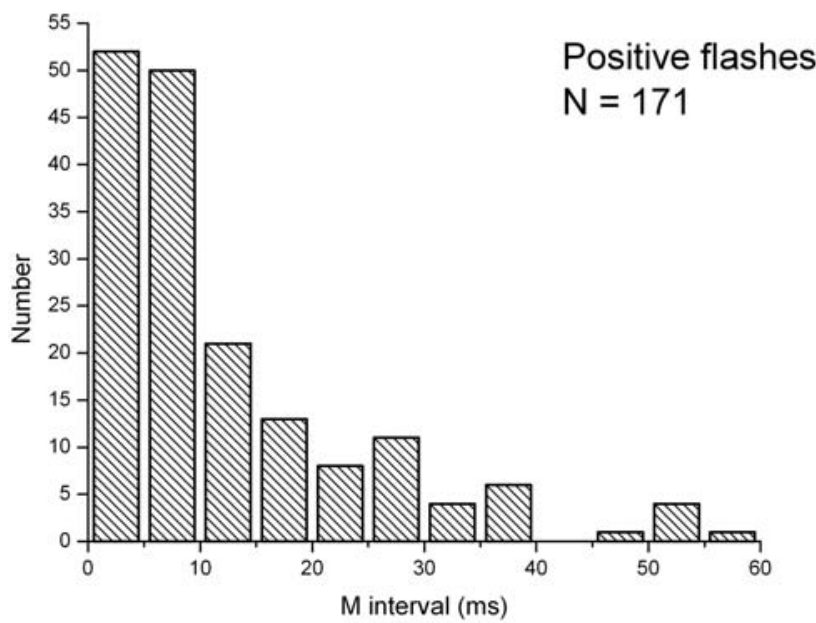

(b)

Figure 2. Time interval between successive $M$ components for (a) negative (93\% of the data set by Campos et al. [2007]) and (b) positive flashes $(99 \%$ of the data set by Campos et al. [2009]). Adapted from Campos et al. [2009, Figure 5 insets] with permission from Elsevier.

sprite initiation are in good agreement with recent observational data for $\mathrm{CC}$ and $\mathrm{M}$ components in $+\mathrm{CG}$ flashes obtained by Campos et al. [2009] even though the parameters they have used were based on the literature for triggered and -CG flashes [Fisher et al., 1993; Thottappillil et al., 1995; Campos et al., 2007].

[15] Asano et al. [2009] have argued that, among the 3 lightning models they considered, case 3 represented the closest approximation to a real positive flash as it represents a RS followed by a CC with superimposed $\mathrm{M}$ components. This argument is based on the CC waveshape statistics presented by Campos et al. [2007], who have reported that types I (more or less exponential decay) and VI (lowintensity plateau) together, occur in $59 \%$ of the -CG cases. Considering the polarity asymmetry in sprite production, the recent work by Campos et al. [2009] corroborates more strongly the argument presented by Asano et al. [2009] favoring case 3 as they have found that types I and VI constitute $67 \%$ of the +CG flashes that were studied.
Table 1 presents a summary of these observational studies [Fisher et al., 1993; Campos et al., 2007, 2009].

[16] The M component elapsed times from the RS used in the simulations made by Asano et al. [2009] (4 to $12 \mathrm{~ms}$ within a $16 \mathrm{~ms}$ long $\mathrm{CC}$ ) was coherent with the observational data obtained by Campos et al. [2009] (see Figure 1). On the other hand, considering typical $\mathrm{CC}$ durations in positive lightning (M. M. F. Saba et al., presented paper, 2007), the relative uniform distribution of $M$ components throughout the CC [Campos et al., 2009] and the observational data on long-delayed sprites [Mika and Haldoupis, 2008], future works would be greatly improved if longer $\mathrm{CC}$ are considered in the simulations (up to hundreds of milliseconds).

[17] Campos et al. [2009] found that the time interval between successive $\mathrm{M}$ components in positive lightning tend to be shorter than in negative lightning [Campos et al., 2007] with a peak of occurrence between 0 and $5 \mathrm{~ms}$ (see Figure 2 and Table 2). Asano et al. [2009] used intervals of either 2 or $4 \mathrm{~ms}$ in their simulations, both values are, thus, coherent with the observational results. Future works, though, might consider longer intervals (up to $20 \mathrm{~ms}$; see Figure 2) in order to analyze more deeply the influence of this parameter over the features of the produced sprite.

[18] One topic that is not discussed in the work of Asano et al. [2009] that should be addressed in future works is the effect of variations in $\mathrm{M}$ component current and charge transfer amplitude. Thottappillil et al. [1995] obtained many parameters of $\mathrm{M}$ components from channel base current measurements in triggered lightning. They said that a typical case "is characterized by a more or less symmetrical current pulse having an amplitude of 100-200 A (2 orders of magnitude lower than that of a typical return stroke [Fisher et al., 1993]), a 10-90\% rise time of 300-500 $\mu \mathrm{s}$ ( 3 orders of magnitude larger than that of a typical return stroke [Fisher et al., 1993]), and a charge transfer to ground of the order of 0.1 to $0.2 \mathrm{C}$ " [Thottappillil et al., 1995, p. 25,711]. Even though the saturation level of their instruments was $1000 \mathrm{~A}$ in one observational site and 2000 A in the other they still have reported 16 cases (out of 124) that have reached the kiloampere range. More recently, other works by Rakov et al. [1998] and Thottappillil [2002], also based on triggered lightning data, have reported a $\mathrm{M}$ component extreme peak current value of $7 \mathrm{kA}$. Asano et al. [2009] have considered in their simulations M components with current amplitude of approximately $20 \mathrm{kA}$ (as inferred from their Figure 2), risetime of $25 \mu \mathrm{s}$, and a charge transfer of $10 \mathrm{C}$. While they have said that changes in the risetime values (of up to $200 \mu \mathrm{s}$ ) have proved to be mostly no influential over the simulation results, similar analysis could be made for the other parameters. Even though the values considered for both current amplitude and charge transfer to ground are 2 orders of magnitude larger than the average values obtained by Thottappillil et al. [1995], they are not so distant from some extreme values presented in the literature [Rakov et al., 1998; Thottappillil, 2002].

[19] As a summary of this comment paper, we believe that Asano et al. [2009] made important contributions to the physics of TLEs with a solid observational basis for the $M$ components temporal parameters. It is necessary to stress, though, that future works would be greatly improved if 
greater care is taken concerning parameters related to the amplitude of $\mathrm{M}$ components and the total duration of the CCs. More realistic lightning models can be obtained if CCs lasting up to hundreds of milliseconds with $\mathrm{M}$ components with amplitudes from hundreds of amperes to a few kiloamperes are considered in the simulations.

[20] Acknowledgments. This research has been supported by $\mathrm{CNPq}$ and FAPESP through the projects 475299/2003-5 and 03/08655-4, respectively. The authors are indebted to an anonymous reviewer for providing valuable comments that enabled several improvements in the paper. One of the authors (L.Z.S.C.) also would like to acknowledge the support given by CNPq through the scholarship 109063/2009-0.

[21] Zuyin Pu thanks Maurício Ballarotti for his assistance in evaluating this paper.

\section{References}

Asano, T., M. Hayakawa, M. Cho, and T. Suzuki (2008), Computer simulations on the initiation and morphological difference of Japan winter and summer sprites, J. Geophys. Res., 113, A02308, doi:10.1029/ 2007JA012528.

Asano, T., T. Suzuki, Y. Hiraki, E. Mareev, M. G. Cho, and M. Hayakawa (2009), Computer simulations on sprite initiation for realistic lightning models with higher-frequency surges, J. Geophys. Res., 114, A02310, doi:10.1029/2008JA013651.

Ballarotti, M. G., M. M. F. Saba, and O. Pinto Jr. (2005), High-speed camera observations of negative ground flashes on a millisecond-scale, Geophys. Res. Lett., 32, L23802, doi:10.1029/2005GL023889.

Barrington-Leigh, C. P., U. S. Inan, M. Stanley, and S. A. Cummer (1999), Sprites directly triggered by negative lightning discharges, Geophys. Res. Lett., 26, 3605-3608, doi:10.1029/1999GL010692.

Bell, T. F., S. C. Reising, and U. S. Inan (1998), Intense continuing currents following positive cloud-to-ground lightning associated with red sprites, Geophys. Res. Lett., 25, 1285-1288, doi:10.1029/98GL00734.

Boccippio, D. J., E. R. Williams, S. J. Heckman, W. A. Lyons, I. T. Baker, and R. Boldi (1995), Sprites, ELF transients, and positive strokes, Science, 269, 1088-1091, doi:10.1126/science.269.5227.1088.

Campos, L. Z. S., M. M. F. Saba, O. Pinto Jr., and M. G. Ballarotti (2007), Waveshapes of continuing currents and properties of M-components in natural negative cloud-to-ground lightning from high-speed video observations, Atmos. Res., 84, 302-310, doi:10.1016/j.atmosres.2006.09.002.

Campos, L. Z. S., M. M. F. Saba, O. Pinto Jr., and M. G. Ballarotti (2009), Waveshapes of continuing currents and properties of M-components in natural positive cloud-to-ground lightning, Atmos. Res., 91, 416-424, doi:10.1016/j.atmosres.2008.02.020.

Cho, M., and M. J. Rycroft (2001), Non-uniform ionization of the upper atmosphere due to the electromagnetic pulse from a horizontal lightning discharge, J. Atmos. Sol. Terr. Phys., 63, 559-580, doi:10.1016/S13646826(00)00235-2.

Cummer, S. A., and M. Füllekrug (2001), Unusually intense continuing current in lightning produces delayed mesospheric breakdown, Geophys. Res. Lett., 28, 495-498, doi:10.1029/2000GL012214.

Fisher, R. J., G. H. Schnetzer, R. Thottappillil, V. A. Rakov, M. A. Uman, and J. D. Goldberg (1993), Parameters of triggered-lightning flashes in Florida and Alabama, J. Geophys. Res., 98, 22,887-22,902, doi:10.1029/ 93JD02293.

Kudintseva, I. G., A. P. Nickolaenko, and M. Hayakawa (2009), Spatial fine structure of model electric pulses in the mesosphere above a $\Gamma$-shaped stroke of lightning, J. Atmos. Sol. Terr. Phys., 71, 603-608, doi:10.1016/ j.jastp.2009.02.002.

Lyons, W. A. (2006), The meteorology of transient luminous events-An introduction and overview, in Sprites, Elves and Intense Lightning Discharges, NATO Sci. Ser. II, vol. 225, edited by M. Füllekrug, E. A. Mareev, and M. J. Rycroft, pp. 19-56, Springer, Dordrecht, Netherlands.

Mika, Á., and C. Haldoupis (2008), VLF studies during TLE occurrences in Europe: A summary of new findings, Space Sci. Rev., 137, 489-510, doi:10.1007/s11214-008-9382-8.

Moudry, D., H. Stenbaek-Nielsen, D. Sentman, and E. Wescott (2003), Imaging of elves, halos and sprite initiation at $1 \mathrm{~ms}$ time resolution, J. Atmos. Sol. Terr. Phys., 65, 509-518, doi:10.1016/S13646826(02)00323-1

Rakov, V. A., R. Thottappillil, and M. A. Uman (1992), Electric field pulses in $\mathrm{K}$ and $\mathrm{M}$ changes of lightning ground flashes, J. Geophys. Res., 97, $9935-9950$

Rakov, V. A., et al. (1998), New insights into lightning processes gained from triggered-lightning experiments in Florida and Alabama, J. Geophys. Res., 103, 14,117-14,130, doi:10.1029/97JD02149.

Saba, M. M. F., O. Pinto Jr., and M. G. Ballarotti (2006), Relation between lightning return stroke peak current and following continuing current, Geophys. Res. Lett., 33, L23807, doi:10.1029/2006GL027455.

Saba, M. M. F., K. L. Cummins, T. A. Warner, E. P. Krider, L. Z. S. Campos, M. G. Ballarotti, O. Pinto Jr., and S. A. Fleenor (2008), Positive leader characteristics from high-speed video observations, Geophys. Res. Lett., 35, L07802, doi:10.1029/2007GL033000.

Saba, M. M. F., L. Z. S. Campos, E. P. Krider, and O. Pinto Jr. (2009), High-speed video observations of positive ground flashes produced by intracloud lightning, Geophys. Res. Lett., 36, L12811, doi:10.1029/ 2009GL038791

São Sabbas, F. T., D. D. Sentman, E. W. Wescott, O. Pinto Jr. O. Mendes Jr., and M. J. Taylor (2003), Statistical analysis of spacetime relationships between sprites and lightning, J. Atmos. Sol. Terr. Phys., 65, 525-535, doi:10.1016/S1364-6826(02)00326-7.

Thottappillil, R. (2002), Electromagnetic pulse environment of cloud-toground lightning for EMC studies, IEEE Trans. Electromagn. Compat., 44, 203-213, doi:10.1109/15.990727.

Thottappillil, R., V. A. Rakov, and M. A. Uman (1990), K and M changes in close lightning ground flashes in Florida, J. Geophys. Res., 95, 18,631-18,640, doi:10.1029/JD095iD11p18631.

Thottappillil, R., J. D. Goldberg, V. A. Rakov, M. A. Uman, R. J. Fisher, and G. H. Schnetzer (1995), Properties of M components from currents measured at triggered lightning channel base, J. Geophys. Res., 100, 25,711-25,720, doi:10.1029/95JD02734.

Williams, E. R. (2006), Problems in lightning physics-The role of polarity asymmetry, Plasma Sources Sci. Technol., 15, S91-S108, doi:10.1088/ 0963-0252/15/2/S12.

Williams, E., E. Downes, R. Boldi, W. Lyons, and S. Heckman (2007), Polarity asymmetry of sprite-producing lightning: A paradox?, Radio Sci., 42, RS2S17, doi:10.1029/2006RS003488.

Yashunin, S. A., E. A. Mareev, and V. A. Rakov (2007), Are lightning M components capable of initiating sprites and sprite halos?, J. Geophys. Res., 112, D10109, doi:10.1029/2006JD007631.

L. Z. S. Campos and M. M. F. Saba, National Institute for Space Research, PO Box 515, São José dos Campos, SP, 12201-970, Brazil. (leandro.zanella@gmail.com) 